This is the peer reviewed version of the following article: " Pastori, G., Wahab, K., Bucci, A., Bellachioma, G., Zuccaccia, C., Llorca, J., Hicham, I. and Alceo Macchioni (2016). Heterogenized water oxidation catalysts prepared by immobilizing Klaui-type organometallic precursors. Chemistry: a european journal, (22), 38: 13459-13463." which has been published in final form at [doi: 10.1002/chem.201602008]. This article may be used for noncommercial purposes in accordance with Wiley Terms and Conditions for SelfArchiving." 


\title{
Heterogenized water oxidation catalysts prepared by immobilizing Klaüi-type organometallic precursors
}

\author{
Gabriele Pastori, ${ }^{[\mathrm{a}]}$ Khaja W. Wahab, ${ }^{[\mathrm{b}]}$ Alberto Bucci, ${ }^{[\mathrm{a}]}$ Gianfranco Bellachioma, ${ }^{\text {[a] }}$ \\ Cristiano Zuccaccia, ${ }^{[a]}$ Jordi Llorca, ${ }^{[c]}$ Hicham Idriss, ${ }^{[b]}$ and Alceo Macchioni* ${ }^{[a]}$
}

[a] Dr. G. Pastori, Dr. A. Bucci, Prof. G. Bellachioma, Prof. Dr. C. Zuccaccia, Prof. Dr. A. Macchioni Department of Chemistry, Biology and Biotechnology and CIRCC

University of Perugia

Via Elce di Sotto 8, I-06123 Perugia, Italy

E-mail: alceo.macchioni@unipg.it

[b] Dr. K. W. Wahab, Prof. Dr. H. Idriss

Corporate Research and Innovation (CRI) Centre at SABIC-KAUST P.O. Box 4545-4700, Thuwal 23955, Saudi Arabia

Email: IdrissH@SABIC.com

[b] Prof. Dr. Jordi Llorca

Universitat Politècnica de Catalunya, Institute of Energy Technologies and Centre for Research in

Nanoengineering, Diagonal 647, 08028 Barcelona, Spain

An efficient and stable heterogenized water oxidation catalyst $\left(2 \_\mathrm{TiO}_{2}\right)$ has been synthesized by immobilizing a novel organo-iridium $\mathrm{Klaüi}^{-t y p e}$ precursor onto rutile- $\mathrm{TiO}_{2}$. Iridium homogeneously distributes at the molecular and atomic/small cluster levels in $2{ }^{-} \mathrm{TiO}_{2}$ and ${ }^{\prime}{ }^{\prime} \mathrm{TiO}_{2}$ (solid catalyst after a catalytic run), respectively, as indicated by STEM-HAADF studies. $2 \mathrm{TiO}_{2}$ exhibits TOF values up to $49.5 \mathrm{~min}^{-1}$ in water oxidation to $\mathrm{O}_{2}$ driven by $\mathrm{NaIO}_{4}$, at $\mathrm{pH}$ close to the neutrality, and a TON limited only by the amount of $\mathrm{NalO}_{4}$ used. $2 \mathrm{TiO}_{2}$ maintains its performances even when contacted for $24 \mathrm{~h}$ with water solutions at both $\mathrm{pH} 14$ (by $\mathrm{KOH}$ ) and $\mathrm{pH} 1$ (by $\mathrm{HNO}_{3}$ ). NMR studies indicate that activation of $2 \mathrm{TiO}_{2}$ likely occurs through the oxidative dissociation of $\mathrm{PO}_{4}{ }^{3-}$.

The development of an efficient catalytic system for the oxidation of water, ${ }^{[1-2]}$ aimed at generating electrons and protons ${ }^{[3]}$ for the photosynthesis of renewable fuels, ${ }^{[4]}$ is one of the most difficult challenges that the scientific community is facing today. Molecular ${ }^{[1]}$ and material ${ }^{[2]}$ water oxidation catalysts (WOCs) with remarkable performances have been reported. Furthermore, it has been recently shown that anchoring a properly tailored homogeneous catalyst onto solid supports, thus obtaining heterogenized WOCs, is a promising strategy to combine the best of two worlds; ${ }^{[5-8]}$ this allows to finely modulating electron density and geometry of WOCs, whereas grafting the latter on solid supports leads to enhanced stability and facilitates catalyst recovering. ${ }^{[5]}$ At the same time, heterogenized WOCs allow the exploitation of metal to be minimized due to the elevate percentage of active centers, in principle, not so different than that in homogeneous catalysis. ${ }^{[5]}$ Klaüi-type compounds (KTCs) $\left[\left(\mathrm{C}_{5} R_{5}\right) \mathrm{M}\left\{\mathrm{P}(\mathrm{O}) \mathrm{R}^{\prime} \mathrm{R}^{\prime \prime}\right\}_{3}\right]^{-}(\mathrm{R}=$ $\mathrm{H}$, Me; $\mathrm{M}=\mathrm{Co}, \mathrm{Rh} ; \mathrm{R}^{\prime}$ and $\mathrm{R}^{\prime \prime}=$ alkyl, aryl, or $\mathrm{O}$-alkyl) ${ }^{[9]}$ attracted our attention as precursors for fabricating heterogenized WOCs because their hydrolysis might generate three $-\mathrm{P}(\mathrm{O})(\mathrm{OH})_{2}$ moieties, particularly suitable for immobilizing them onto properly selected functional materials. Generally speaking, KTCs have been widely used as monoanionic terdentate ligands to stabilize coordination complexes and organometallics of almost all metals of the periodic table. ${ }^{[10]}$ The derived compounds have found application in several fields, including homogeneous catalysis, lithium selective transportation across membranes $^{[11]}$ and extraction of alkali metal ions, magnesium and calcium ions. ${ }^{[12]}$ It has also been attempted to anchor KTCs onto solid supports with the main aim of generating novel exchange materials and heterogenized catalysts. ${ }^{[13]}$ In all cases, KTCs have been used as ligands and no investigation has been carried out to explore the possible catalytic activity of the M-metal center. This could be related to the fact that, being 18-electrons saturated compounds, they are supposed to have little propensity to 
coordinate and activate a substrate. Nevertheless, we thought that such a possible drawback could be not so crucial in WO because a coordinative position might be generated by the oxidative elimination of meta phosphoric acid $\mathrm{P}(\mathrm{O})_{2}(\mathrm{OH})$ (see below) or by the oxidative transformation of the $-\mathrm{C}_{5} \mathrm{R}_{5}$ ligand. ${ }^{[14]}$
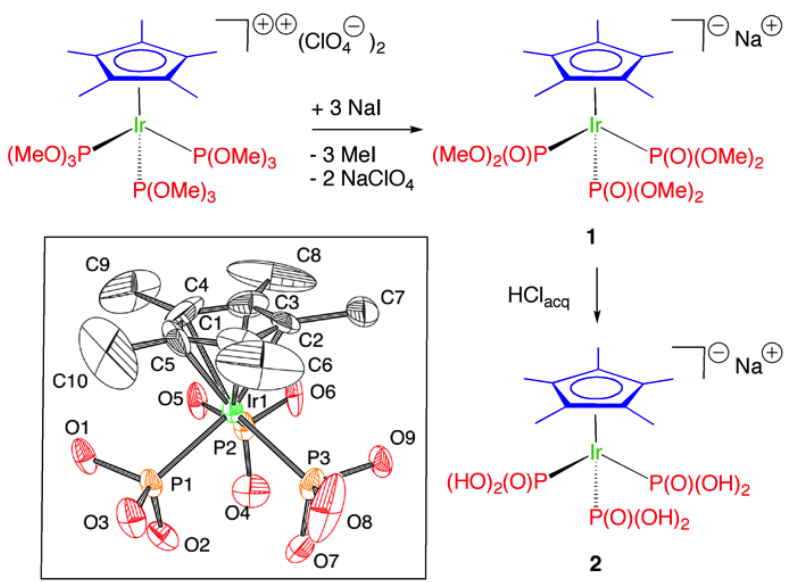

Scheme 1. Synthesis and an ORTEP view of complex 2. Ellipsoids are drawn at the $50 \%$ probability level. Selected bond distances $(\AA)$ and angles $(\mathrm{deg})$ : Ir-P1 $=2.277, \mathrm{Ir}-\mathrm{P} 2=2.276, \mathrm{Ir}-\mathrm{P} 3=2.267, \mathrm{Ir}-\mathrm{Cp}^{*}=1.935, \mathrm{P} 1-\mathrm{O} 1=1.564$, $\mathrm{P} 1-\mathrm{O} 2=1.581, \mathrm{P} 1-\mathrm{O} 3=1.564 ; \mathrm{P} 1-\mathrm{Ir}-\mathrm{P} 2=74.88, \mathrm{P} 2-\mathrm{Ir}-\mathrm{P} 3=90.72, \mathrm{P} 3-\mathrm{Ir}-\mathrm{P} 1=93.76, \mathrm{Cp}^{*}-\mathrm{Ir}-\mathrm{P} 1=122.89, \mathrm{Cp} \mathrm{P}^{*}$ $\mathrm{Ir}-\mathrm{P} 2=123.84, \mathrm{Cp}{ }^{*}-\mathrm{Ir}-\mathrm{P} 3=125.34 . \mathrm{Cp}^{*}$ is the centroid of the $\mathrm{C} 1, \mathrm{C} 2, \mathrm{C} 3, \mathrm{C} 4$ and $\mathrm{C} 5$ atoms.

Herein we report the synthesis and characterization of a novel KTC $\left[C p^{*} \operatorname{Ir}\left\{\mathrm{P}(\mathrm{O})(\mathrm{OH})_{2}\right\}_{3}\right] \mathrm{Na}(2)$ and show that it is a competent WOC and, more importantly, a particularly suitable precursor to be anchored onto $\mathrm{TiO}_{2}$ providing a heterogenized WOC, which exhibits remarkable activity and robustness. Complex 1 was synthesized according to the literature, ${ }^{[15]}$ reacting $\left[\mathrm{Cp}^{*} \mathrm{IrCl}(\mu-\mathrm{Cl})\right]_{2}$ with $\mathrm{P}(\mathrm{OMe})_{3}$ in the presence of $\mathrm{AgClO}_{4}$ followed by the oxidative transformation of the three $\mathrm{Ir}-\mathrm{P}(\mathrm{OMe})_{3}$ moieties into $\mathrm{Ir}-\mathrm{P}(\mathrm{O})(\mathrm{OMe})_{2}$ by the Michaelis-Arbuzov type reaction (Scheme 1). ${ }^{[16]} 2$ was obtained by the hydrolysis of 1 with $3 \mathrm{M} \mathrm{HCl}$ (Scheme 1, SI) as a pale yellow solid that changes its color when scratched with a spatula, becoming red and, successively, dark brown. Interestingly, once dissolved in water, acetone, and other solvents, it provides yellow solutions that give-back a pale yellow powder once the solvent is removed. The latter undergoes the same change of color when manipulated with a spatula. This reversible behavior is typical of mechanochromic materials. ${ }^{[17]}$ The solid structure of $\mathbf{2}$ was determined by X-Ray single crystal studies. The intramolecular structure (Scheme 1) does not reveal any particular feature with the exception of a rather long Ir-Cp* distance $(1.935 \AA)$. This indicates that the three $\mathrm{P}(\mathrm{O})(\mathrm{OH})_{2}{ }^{-}$ligands provide high electron density at the metal center making the $\mathrm{Cp}^{*}$ coordination weaker than usual. Consistently, the $\mathrm{C}_{-}$ Me quaternary carbons resonate at rather high chemical shift $(101.9 \mathrm{ppm})$ in the ${ }^{13} \mathrm{C}$ NMR spectrum. ${ }^{[18]}$ The intermolecular structure exhibits an alternation of hydrophobic and hydrophilic layers constituted by $\mathrm{Cp}^{*}$ and $\mathrm{Ir}-\mathrm{P}(\mathrm{O})(\mathrm{OH})_{2}$ moieties, respectively, of different molecular units $(\mathrm{SI}) .2$ was heterogenized by contacting ca. $5 \mathrm{ml}$ of a water solution $\left(3-4 \cdot 10^{-3} \mathrm{M}\right)$ with dispersed rutile- $\mathrm{TiO}_{2}(1 \mathrm{~g})$ at room temperature for $24 \mathrm{~h}$, following the course of heterogenization by monitoring the intensity decrease of the ${ }^{31} \mathrm{P}$ NMR resonance of 2 . The resulting $2 \mathrm{TiO}_{2}$ material was washed with water, a $0.1 \mathrm{M} \mathrm{HNO}_{3}$ solution, acetonitrile and dichloromethane, before drying it under vacuum. The loading of iridium, as evaluated by ICP-OES analysis, was $8.54 \mu \mathrm{M} / \mathrm{g} .2 \mathrm{TiO}_{2}$ was structurally characterized by solid-state NMR spectroscopy and STEM-HAADF (scanning transmission electron microscopy - high angle annular dark field) (SI). Figure 1 shows a comparison between the ${ }^{31} \mathrm{P}$ and ${ }^{13} \mathrm{C}$ CP MAS NMR spectra of precursor 2, $2 \mathrm{TiO}_{2}$ and a sample recovered after a catalytic run $\left(\mathbf{2}^{\prime}, \mathrm{TiO}_{2}\right)$. Consistently with the literature, heterogenization of $\mathbf{2}$ onto $\mathrm{TiO}_{2}$ causes a shift to lower frequencies of carbon and phosphorous resonances. ${ }^{[19]}$ Furthermore, a remarkable broadening of ${ }^{31} \mathrm{P}$ resonance is observed likely due to the different binding modalities of $\mathrm{Ir}-\mathrm{P}(\mathrm{O})(\mathrm{OH})_{2}$ moieties and typologies of $\mathrm{TiO}_{2}$ superficial sites. A sharper resonance is present at $-0.8 \mathrm{ppm}$ reasonably due to the oxidative detachment of a phosphate group that binds in a monodentate fashion to $\mathrm{TiO}_{2}{ }^{[20]}$ Such a resonance is present in higher percentage in 2' $\mathrm{TiO}_{2}$, whereas the intensity of the broader resonances is substantially reduced. Also ${ }^{13} \mathrm{C}$ NMR resonances due to $\mathrm{Cp}^{*}$ have a dramatic lower 
intensity in the spectrum of 2' ${ }^{-} \mathrm{TiO}_{2}$ compared with that of $2 \mathrm{TiO}_{2}$. The reasons of these observations are discussed below after having reported the catalytic results. $\overline{\mathrm{STEM}}$-HAADF studies of $2 \mathrm{TiO}_{2}$ indicate that the sample contains $\mathrm{TiO}_{2}$ particles very well dispersed and quite homogeneous in size, about $20 \times 40 \mathrm{~nm}$. A general view of the sample is depicted in Figure 2. At high levels of magnification, besides the $\mathrm{TiO}_{2}$ support crystallites, both 2_- $\mathrm{TiO}_{2}$ and 2'- TiO shows extremely small Ir clusters (at the limit of the microscope sensitivity), ranging from 0.2 to $0.4 \mathrm{~nm}$ (Figure 2). Assuming a Gaussian particle size distribution, even smaller clusters, which escape STEM detection, should be present. In the STEMHAADF images the clusters are hardly seen, as brighter spots on the $\mathrm{TiO}_{2}$ crystallites. All seems to indicate that $\mathrm{Ir}$ is atomically distributed or forms very small clusters in both 2_ $\mathrm{TiO}_{2}$ and 2', $\mathrm{TiO}_{2}$. Given the small particle size no EDS analysis was reliable. It is important to note that these metallic clusters are not formed upon electron beam exposure, that is, they are not the result of electron damage on the sample. This has been carefully checked by using different electron dosage over the sample.

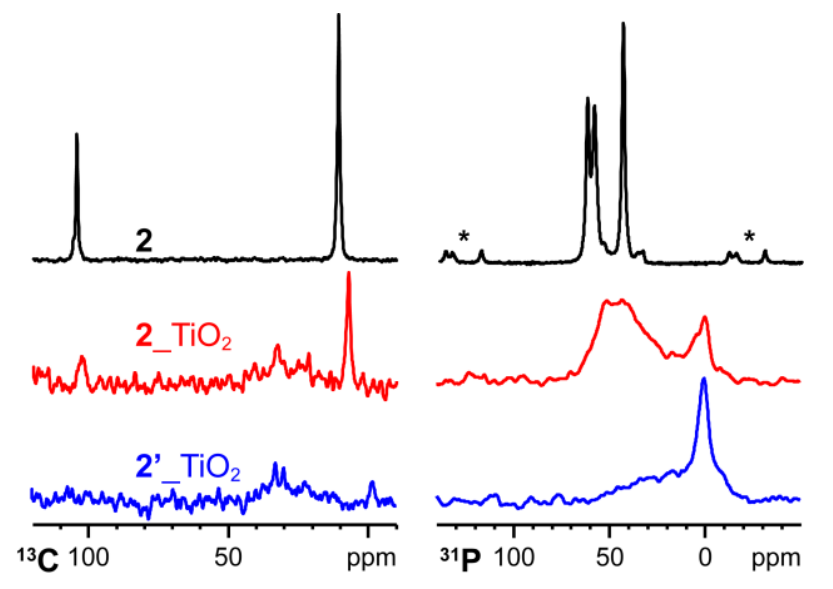

Figure 1. ${ }^{13} \mathrm{C}\left\{{ }^{1} \mathrm{H}\right\}$ (left) and ${ }^{31} \mathrm{P}\left\{{ }^{1} \mathrm{H}\right\}$ (right) CPMAS NMR spectra of 2 (black), 2_ $\mathrm{TiO}_{2}$ (red) and 2'_ $\mathrm{TiO}_{2}$ (blue). Asterisks denote spinning side bands.

1, 2 and $2 \mathrm{TiO}_{2}$ were tested as WOCs using cerium ammonium nitrate (CAN) and $\mathrm{NalO}_{4}$ as chemical sacrificial oxidants, monitoring the reaction by manometry and Clark electrode. Selected results are reported in Table 1 (complete data set is given in $\mathrm{SI}$ ). Complex 1 is not active at all with CAN and exhibits just a poor catalytic activity with $\mathrm{NaIO}_{4}$, affording only 26 cycles with a TOF $=0.1 \min ^{-1}$ (Tab. 1, entries 1 2). On the contrary complex 2 is an efficient WOC with both oxidants, capable of completing all cycles expected based on the concentration of the employed sacrificial oxidant with TOF up to $30 \mathrm{~min}^{-1}$ and 50 $\mathrm{min}^{-1}$ with CAN and $\mathrm{NalO}_{4}$, respectively (Tab. 1, entries 3-6). The catalytic activity of 2 was strongly affected by the $\mathrm{pH}$ of the reaction medium. This was clearly demonstrated by adding an increased amount of $\mathrm{KOH}$ to the solution of 2 before the injection of a solution of $\mathrm{NalO}_{4}(\mathrm{SI})$. TOF of oxygen production remains substantially the same (about $6 \mathrm{~min}^{-1}$ ) when 1-4 equivalents of $\mathrm{KOH}$ were added (SI), but it markedly increases up to $49.5 \mathrm{~min}^{-1}$ when 16 equivalents of $\mathrm{KOH}$ were added (Tab. 1, entry 6). Also 2_ $\mathrm{TiO}_{2}$ is an active WOC with both $\mathrm{CAN}$ and $\mathrm{NalO}_{4}$; however an almost complete leaching of the catalyst occurs with CAN, already after the first catalytic run (Tab. 1, entries 7-9). This is likely due to the high tendency of KTCs to act as terdentate ligand for the oxophylic $\mathrm{Ce}^{4+} \cdot{ }^{[1]}$ For that reason we focused our attention on the catalytic activity of $2 \mathrm{TiO}_{2}$ with $\mathrm{NalO}_{4}$ as sacrificial oxidant. $2 \mathrm{TiO}_{2}$ exhibited a catalytic activity similar to 2 (compare entries 10 and 5 in Tab. 1) and did not undergo any leaching as demonstrated by the complete inactivity of the supernatant (Tab. 1, entry 11) and observation of comparable TOF and TON values for the second (Tab. 1, entry 12) and other consecutive runs (SI). Addition of 16 equivalents of $\mathrm{KOH}$ caused a remarkable increase of TOF, from $2.8 \mathrm{~min}^{-1}$ to $19.8 \mathrm{~min}^{-1}$ (entries 13-14, Tab. 1), analogously to what observed for 2. Three successive runs were performed after having washed the solid catalyst with water (SI); all expected cycles were completed and the original TOF in absence of $\mathrm{KOH}$ is gradually restored. Two additional runs were carried out after having left the catalyst in contact with a water solution at $\mathrm{pH} 10$ and $\mathrm{pH} 14$ for $24 \mathrm{~h}$, respectively, and washed with water (SI); the catalyst maintains its performances both in terms of TON and TOF and the supernantant is not 
active in both cases suggesting no leaching. Finally, in order to further explore the stability of the catalyst, three independent catalytic experiments were carried out (Tab. 1, entries 15-17), utilizing exactly the same concentration of $2 \mathrm{TiO}_{2}$ and $\mathrm{NaIO}_{4}$, with the standard protocol (Tab. 1, entry 15), contacting $2 \mathrm{TiO}_{2}$ with a water solution at $\mathrm{pH} 14$ (by KOH) for $24 \mathrm{~h}$ ( $\mathrm{Tab}$. 1, entry 16) and contacting $2 \mathrm{TiO}_{2}$ with a solution at $\mathrm{pH} 1$ (by $\mathrm{HNO}_{3}$ ) (Tab. 1, entry 17). In all three runs, oxygen production was almost quantitative; TOF value after prolonged contact with the strongly basic solution was more than two times higher $\left(6.8 \mathrm{~min}^{-1}\right.$ vs $2.4 \mathrm{~min}^{-1}$ ) consistently with what said above, whereas TOF value after contacting with the acidic one is substantially the same than the original TOF value $\left(2.3 \mathrm{~min}^{-1}\right.$ vs $\left.2.4 \mathrm{~min}^{-1}\right)$.

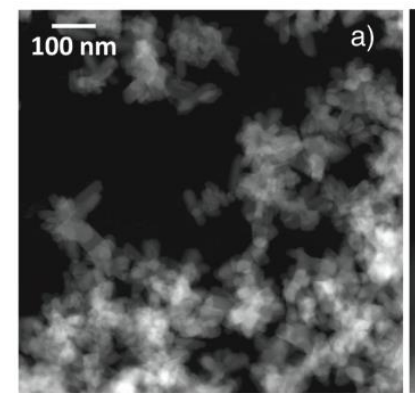

c)
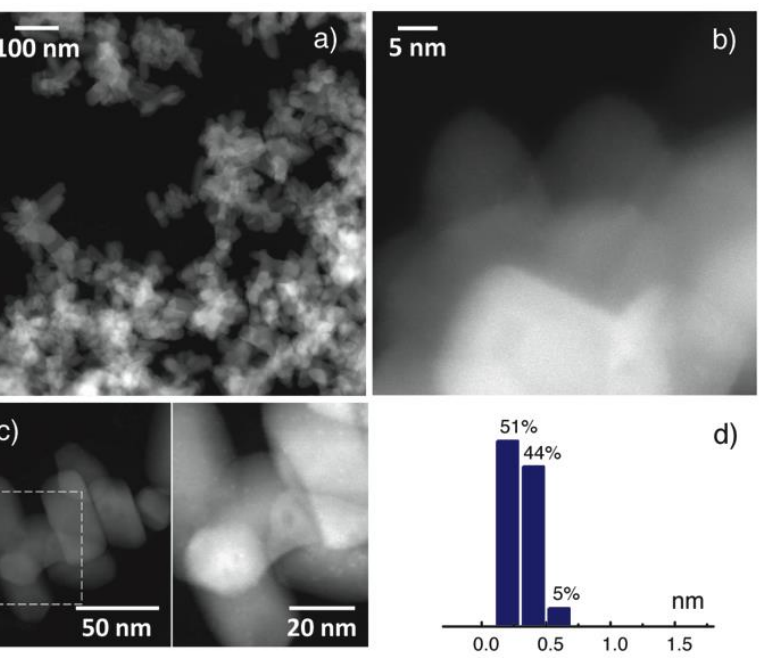

Figure 2. a) and c) STEM-HAADF images of $2 \mathrm{TiO}_{2}$ at different levels of magnification; b) A STEM-HAADF image of 2' $\mathrm{TiO}_{2}$ at the maximum level of magnification; d) Size distribution of Ir-particles in 2'- $\mathrm{TiO}_{2}$.

$\mathrm{pH}$ was measured for all steps related to a catalytic experiment in which a suspension $19.1 \mathrm{mM}$ of $2 \mathrm{TiO}_{2}$ was reacted with a solution of $9.1 \mathrm{mM}$ of $\mathrm{NaIO}_{4}$, in the presence of 16 equivalents of $\mathrm{KOH}$. Specifically, $\mathrm{pH}$ changed from 5.10 to 4.41 when $2 \mathrm{TiO}_{2}$ was dispersed in deionized water. The addition of $\mathrm{KOH}$ caused an increase of $\mathrm{pH}$ up to 9.60, whereas injection of $\mathrm{NalO}_{4}$ led to a $\mathrm{pH}=6.32$ that remained substantially unaltered until the end of catalysis. The observed acidification caused by $\mathrm{NalO}_{4}$ addition can be explained considering that $\mathrm{IO}_{4}{ }^{-}$undergoes hydration with two water molecules leading to the weak acid $\mathrm{H}_{4} \mathrm{IO}_{6}{ }^{-[22]}$

Table 1. Selected catalytic data for WOCs obtained by manometry.

\begin{tabular}{|c|c|c|c|c|c|}
\hline Entry & $\begin{array}{l}\mathrm{C}_{\text {Cat }} \\
(\mu \mathrm{M})\end{array}$ & $\begin{array}{l}\mathrm{C}_{\mathrm{Ox}} \\
(\mathrm{mM})\end{array}$ & $\begin{array}{l}\text { TOF } \\
\left(\min ^{-1}\right)\end{array}$ & TON & $\mathrm{O}_{2}$ yield \\
\hline \multicolumn{6}{|l|}{ Cat 1} \\
\hline 1 & 5.0 & CAN/10.0 & - & - & - \\
\hline 2 & 1.0 & $\mathrm{NaIO}_{4} / 10.0$ & 0.1 & 26 & $5 \%$ \\
\hline \multicolumn{6}{|l|}{ Cat 2} \\
\hline 3 & 5.0 & CAN/10.0 & 29.9 & 496 & $99 \%$ \\
\hline 4 & 1.0 & $\mathrm{NalO}_{4} / 10.0$ & 9.6 & 3299 & $66 \%$ \\
\hline 5 & 18.2 & $\mathrm{NaIO}_{4} / 9.1$ & 3.0 & 230 & $92 \%$ \\
\hline $616^{\mathrm{eq}} \mathrm{KOH}$ & 5.0 & $\mathrm{NaIO}_{4} / 10.0$ & 49.5 & 980 & $98 \%$ \\
\hline \multicolumn{6}{|l|}{ Cat $2 \mathrm{TiO}_{2}$} \\
\hline $7 \mathrm{I}_{\text {solid }}$ & 20.0 & CAN/10.0 & 63.8 & 93 & $77 \%$ \\
\hline
\end{tabular}




$\begin{array}{lccccc}8 \mathrm{I}_{\text {supernatant }} & \text { n.a. } & \mathrm{CAN} / 10.0 & \text { n.a. } & 100 & 83 \% \\ 9 \mathrm{I}_{\text {solid }} & \text { n.a. } & \mathrm{CAN} / 10.0 & \text { n.a. } & 22 & 19 \% \\ 10 \mathrm{I}_{\text {solid }} & 19.3 & \mathrm{NaIO}_{4} / 9.1 & 2.8 & 200 & 85 \% \\ 11 \mathrm{I}_{\text {supernatant }} & \text { n.a. } & \mathrm{NaIO}_{4} / 9.1 & \text { n.a. } & \text { n.a. } & 0 \% \\ 12 \mathrm{II}_{\text {solid }} & 19.3 & \mathrm{NaIO}_{4} / 9.1 & 2.8 & 212 & 90 \% \\ 13 \mathrm{I}_{\text {solid }} & 19.3 & \mathrm{NaIO}_{4} / 9.1 & 2.8 & 200 & 85 \% \\ 14 \mathrm{II}_{\text {solid }} 16^{\text {eq }} \mathrm{KOH} & 19.3 & \mathrm{NaIO}_{4} / 9.1 & 19.8 & 218 & 92 \% \\ 15 & 19.1 & \mathrm{NaIO}_{4} / 9.1 & 2.4 & 210 & 88 \% \\ 16^{\text {a }} & 19.1 & \mathrm{NaIO}_{4} / 9.1 & 6.8 & 220 & 92 \% \\ 17^{\text {b }} & 19.1 & \mathrm{NaIO}_{4} / 9.1 & 2.3 & 206 & 86 \%\end{array}$

${ }^{a}$ Run performed after having left the catalytic suspension at $\mathrm{pH}=14$ for $24 \mathrm{~h} .{ }^{\mathrm{b}}$ Run performed after having left the catalytic suspension at $\mathrm{pH}=1$ for $24 \mathrm{~h}$.

In order to understand the modality of activation of $\mathbf{2}$ and $\mathbf{2} \mathrm{TiO}_{2}$ and the reason why $\mathbf{1}$, contrary to $\mathbf{2}$, exhibits poor catalytic activity, preliminary NMR studies were performed. ${ }^{1} \mathrm{H}$ and ${ }^{31} \mathrm{P}$ NMR spectra of a solution 1-5 mM of 1 were found to be substantially unaffected by the addition of up to 16 equivalents of $\mathrm{KOH}$ and several equivalents of $\mathrm{NalO}_{4}$. On the contrary, ${ }^{1} \mathrm{H}$ and ${ }^{31} \mathrm{P}$ NMR spectra of 2 showed a shift of resonances to lower frequency as increasing amounts of $\mathrm{KOH}$ were added, consistent with the gradual deprotonation of acidic functionalities. More importantly, the multiple-addition of 0.25 equivalents of $\mathrm{NaIO}_{4}$ nicely tracks with the quantitative appearance of a ${ }^{31} \mathrm{P}$ NMR resonance assigned to $\mathrm{PO}_{4}{ }^{3-}$ (SI). Contemporary, the intensity of the ${ }^{1} \mathrm{H}$ NMR Cp${ }^{*}$ resonance of 2 (a quartet due the H-P scalar coupling with ${ }^{31} \mathrm{P}$ ) decreases and singlet appears at $1.50 \mathrm{ppm}$, suggesting elimination of all P-moieties. Oxidative transformation of $\mathrm{Cp}^{*}$, as indicated by the appearance of ${ }^{\top} \mathrm{H}$ resonances due to acetic and formic acids, ${ }^{[23]}$ starts successively to $\mathrm{PO}_{4}{ }^{3-}$ elimination. It can be concluded that 2 easily transforms into a $\mathrm{Cp}^{*} \operatorname{Ir} \mathrm{X}_{3^{-}}$ species ( $\mathrm{X}=$ anionic species or water) by the oxidative elimination of $\mathrm{PO}_{4}{ }^{3-}$, asking for the presence of a $\mathrm{P}-\mathrm{O}-\mathrm{H}$ functionality as illustrated in Scheme 2 . This might explain why 1 is not an active WOC.

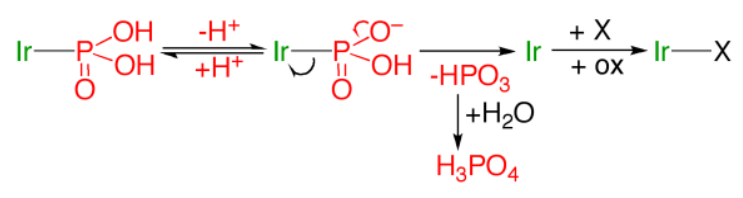

Scheme 2. Modality of activation of 2.

Interestingly, a coordination vacancy appears to be necessary in order to initiate the oxidative transformation of $\mathrm{Cp}^{*}$ and this not the case in 2 which cannot undergo the expulsion of a $-\mathrm{P}(\mathrm{O})(\mathrm{OMe})_{2}$ unit. Solid-state ${ }^{31} \mathrm{P}$ NMR spectrum shows that some $\mathrm{PO}_{4}{ }^{3-}$ is already present in $2 \mathrm{TiO}_{2}$ before catalysis, likely derived from oxidative dissociation (photo)catalyzed by $\mathrm{TiO}_{2}$, and it substantially increases after a catalytic run (Figure 1). Nevertheless, a broad band centered at $24.7 \mathrm{ppm}$ is still present. It can be speculated that the latter is due to some iridium centers missing the $\mathrm{Cp}^{*}$, still bearing a bonded phosphate group. In conclusion, it has been demonstrated, for the first time, that KTCs, bearing $\mathrm{P}(\mathrm{O})(\mathrm{OH})_{2}$ functionalities, are excellent precursors for the fabrication of heterogenized catalysts for WO. The resulting iridium- $\mathrm{TiO}_{2}$ hybrid material exhibits remarkable TOF and TON performances in WO driven by $\mathrm{NaIO}_{4}$ and an extremely low propensity to leaching. This strategy appears to be rather general and many extensions can be envisioned. For example, the nature of KTC metal center, especially considering cheap metals, and support can be changed. At the same time, photochemical and electrochemical tests have to be performed. All these experiments are in progress in our laboratories and results will be reported in due time. 


\section{Acknowledgements}

Financial support from SABIC and Fondazione Cassa di Risparmio di Perugia (2015.0338.021) is kindly acknowledged. JL is Serra Húnter Fellow and is grateful to the ICREA Academia Program and MINECO grant ENE2015-63969-R.

Keywords: water oxidation • iridium • titania $\bullet$ Klaüi-type compounds $\bullet$ water splitting

[1] a) Molecular Water Oxidation (Ed.: A. Llobet), Wiley-Interscience, New York, 2014; b) M. D. Kärkäs, O. Verho, E. V. Johnston, B. Åkermark, Chem. Rev. 2014, 114, 11863-12001; c) J. D. Blakemore, R. H. Crabtree, G. W. Brudvig, Chem. Rev. 2015, 115, 12974-13005; d) F. Evangelisti, R. More, F. Hodel, S. Luber, G. R. Patzke, J. Am. Chem. Soc. 2015, 137, 11076-11084.

[2] F. E. Osterloh, Chem. Mater. 2008, 20, 35-54.

[3] a) K. J. Young, L. A. Martini, R. L. Milot, R. C. Snoeberger III, V. S. Batista, C. A. Schmuttenmaer, R. H. Crabtree, G. W. Brudvig, Coord. Chem. Rev. 2012, 256, 2503-2520; b) A. Kudo, Y. Miseki Chem. Soc. Rev. 2009, 38, 253-278.

[4] a) N. S. Lewis, D. G. Nocera, Proc. Natl. Accad. Sci. 2006, 103, 15729-15735; b) N. S. Lewis, Nature 2001, 414, 589-590; c) V. Balzani, A. Credi, M. Venturi, ChemSusChem 2008, 1, 26-58; d) T. J. Meyer, Nature 2008, 451, 778-779.

[5] a) C. Coperet, M. Chabanas, R. P. Saint-Arroman, J. M. Basset, Angew. Chem. Int. Ed. 2003, 42, 156-181; b) Heterogenized Homogeneous Catalysts for Fine Chemicals Production Eds.: P. Barbaro and F. Liguori), Springer, Dordrecht, 2010.

[6] J.-M. Savéant, Chem. Rev. 2008, 108, 2348-2378.

[7] A. Macchioni, Proc. SPIE 9176 2014, Solar Hydrogen and Nanotechnology IX, 917608; doi:10.1117/12.2060957.

[8] a) C. Wang, J.-L Wang, W. Lin, J. Am. Chem. Soc. 2012, 134, 19895-19908; b) A. Savini, A. Bucci, M. Nocchetti, R. Vivani, H. Idriss, A. Macchioni, ACS Catal. 2015, 5, 264-271; c) S. W. Sheehan, J. M. Thomsen, H. Hintermair, R. H. Crabtree, G. W. Brudvig, C. A. Schmuttenmaer, Nat. Commun. 2015, DOI: 10.1038/ ncomms7469; d) Y. Gao, X. Ding, J. Liu, L. Wang, Z. Lu, L. Li, L. Sun, J. Am. Chem. Soc. 2013, 135, 42194222; e) K. S. Joya, N. K. Subbaiyan, F. D'Souza, H. J. M. de Groot, Angew. Chem. Int. Ed. 2012, 51, 96019605.

[9] W. Klaüi, Angew. Chem. Int. Ed. Engl. 1990, 29, 627-637.

[10] W.-H. Leung, Q.-F. Zhang, X.-Y. Yi, Coord. Chem. Rev. 2007, 251, 2266-2279.

[11] H. Shinar, G. Navon, W. Klaüi, J. Am. Chem. Soc. 1986, 108, 5005-5006.

[12] H. Bukowsky, E. Uhlemann, W. Klaüi, Anal. Chim. Acta 1996, 319, 271-274.

[13] a) W. Klaüi, N. Mocigemba, A. Weber-Schuster, R. Bell, W. Frank, D. Mootz, W. Poll, H. Wunderlich, Chem. Eur. J. 2002, 8, 2335-2340; b) E. Bae, W. Choi, J. Park, H. S. Shin, S. B. Kim, J. S. Lee, J. Phys. Chem. B 2004, 108, 14093-14101.

[14] C. Zuccaccia, G. Bellachioma, O. Bortolini, A. Bucci, A. Savini, A. Macchioni, Chem. Eur. J. 2014, 20, 34463456 and references therein.

[15] M. Scotti, M. Valderrama, P. Campos, W. Klaüi, Inorg. Chim. Acta 1993, 207, 141-145.

[16] T. B. Brill, S. J. Landon, Chem. Rev. 1984, 84, 577-585.

[17] K. Ariga, T. Mori, J. P. Hill, Adv. Mater. 2012, 24, 158-176.

[18] Typical ${ }^{13} \mathrm{C}$ chemical shift values for $\mathrm{C}-\mathrm{CH}_{3}$ quaternary carbon is about 80-90 ppm: A. Savini, A. Bucci, G. Bellachioma, S. Giancola, F. Palomba, L. Rocchigiani, A. Rossi, M. Suriani, C. Zuccaccia, A. Macchioni, J. Organomet. Chem. 2014, 771, 24-32.

[19] G. Guerrero, P. H. Mutin, A. Vioux, Chem . Mater. 2001, 13, 4367-4373.

[20] D. Lahcène, A. Ayral, B. Boury, R. M. Laine, J. Colloid Interface Sci. 2013, 393, 335-339.

[21] X.-Y. Yi, T. C. H. Lam, I. D. Williams, W.-H. Leung, Inorg. Chem. 2010, 49, 2232-2238.

[22] R. M. Kren, H. W. Dodgen, C. J. Nyman, Inorg. Chem. 1968, 7, 446-451.

[23] a) A. Savini, P. Belanzoni, G. Bellachioma, C. Zuccaccia, D. Zuccaccia, A. Macchioni, Green Chem. 2011, 13, 3360-3374; b) D. B. Grotjahn, D. B. Brown, J. K. Martin, D. C. Marelius, M.-C. Abadjian, H. N. Tran, G. Kalyuzhny, K. S. Vecchio, Z. G. Specht, S. A. Cortes-Llamas, V. Miranda-Soto, C. van Niekerk, C. E. Moore, A. L. Rheingold, J. Am. Chem. Soc. 2011, 133, 19024-19027. 